\title{
Is aspirin safe for patients with heart failure?
}

\author{
John G F Cleland, Christopher J Bulpitt, Rodney H Falk, Iain N Findlay, Celia M Oakley, \\ Gordon Murray, Philip A Poole-Wilson, Colin R M Prentice, George C Sutton
}

\section{Glossary}

AMIS = Aspirin Myocardial Infarction Study Research Group

ISIS-2 = International Study of Infarct Survival (second (tudy)

tudy)

PARIS-II = Persantine-

Aspirin Reinfarction Study SAPAT = Swedish Angina Pectoris Angina Trial SAVE = Survival and Ventricular Enlargement SOLVD = Studies of Left Ventricular Dysfunction $\mathrm{V}-\mathrm{HeFT}=$ Veterans Hear Failure Trial

\section{Western Infirmary, Glasgow \\ J G F Cleland \\ Boston University Medical Centre, Boston, Mass., USA R H Falk \\ Royal Alexandra Hospital, Paisley I N Findlay \\ Royal Postgraduate \\ Medical School, Hammersmith Hospital, London C M Oakley C J Bulpitt}

Robertson Centre for Biostatistics, Glasgow G Murray

Royal Brompton National Heart and Lung Institute, London

P A Poole-Wilson

Leeds General Infirmary, Leeds C R M Prentice Hillingdon Hospital, Uxbridge G C Sutton

Correspondence to: Dr J G F Cleland, British Dr J G F Cleland, British Heart Foundation Senio Research Fellow, MRC Clinical Research Initiative in Heart Failure and Honorary Consultant Cardiologist, University of Glasgow, G12 8QQ Accepted for publication 27 March 1995
Despite evidence that ACE inhibitors can improve the prognosis of patients with heart failure, mortality remains high even when symptoms are mild. The SOLVD studies have highlighted the contribution of coronary ischaemic events to subsequent outcome among patients with substantial ventricular dysfunction. In the presence of pre-existing left ventricular dysfunction a myocardial infarction carries a $50 \%$ mortality within three months of the event compared with a mortality of only $20 \%$ at four years among those who have had no such event. ${ }^{1}$ Aspirin is widely used in patients with coronary disease, a common cause of heart failure, to try to reduce the frequency of myocardial infarction and death. However, enalapril did not improve prognosis among patients with heart failure taking aspirin in the SOLVD study, a finding that has not been well publicised. ${ }^{2}$

There are at least three possible explanations for the lack of apparent benefit with enalapril among those taking aspirin in the SOLVD trial. The interaction between aspirin and enalapril was statistically significant $(P<0.01)$ but was not pre-planned. The lack of benefit from ACE inhibition among those taking aspirin could have occurred by chance, an explanation favoured by the trialists. Alternatively, aspirin may negate the benefits of ACE inhibition. This would be a potentially serious and costly interaction. Finally, it is possible that some of the mortality benefit from ACE inhibition can be achieved by aspirin alone and that ACE inhibitors confer no additional advantage. If this were the case the less expensive option would be attractive.

The benefits of ACE inhibitors are well established but the safety and efficacy of aspirin in heart failure have not been studied. This article is devoted to examining the arguments for and against aspirin in heart failure and the potential interaction with ACE inhibitors. The reader should be aware from the outset that the evidence of harm or benefit with aspirin in this group of patients is entirely inconclusive.

\section{Should aspirin be administered to patients with heart failure and coronary disease?}

EVIDENCE FROM POST-INFARCTION STUDIES

The most common underlying cause of heart failure in patients under the age of 75 years in industrialised societies is ischaemic heart disease. $^{3}$
The Aspirin Trialists recently suggested that the benefits of aspirin in patients with coronary artery disease were "extraordinarily definitely established" based on a meta-analysis including the ISIS-2 study, a study that lasted only 35 days of patients who had had an acute myocardial infarction. A treatment that works in the acute state may have a different effect in the chronic condition. ISIS-2 is the only trial of aspirin to show a significant reduction in mortality in patients with ischaemic heart disease.

A meta-analysis of all the post-infarction, long term antiplatelet agent trials published in 1988 suggested that such treatment would save about 4 lives per thousand per year. ${ }^{4}$ The 1994 meta-analysis, in which one additional trial had been added and the numbers of deaths reported in the previous metaanalysis had changed, suggested a reduction in total mortality (about 6 lives saved per 1000 patients treated per year) with antiplatelet treatment. ${ }^{5}$ The 1988 meta-analysis did not report whether the reduction in total mortality was significant or not. The level of statistical significance achieved in the 1994 meta-analysis $(P=0.02)$ was not substantial given the size of population studied, the number of analyses performed, and the fact that the number of deaths reported in some of the studies had changed long-after the studies had been unblinded. The result gives rise to even more concern because meta-analysis has failed to predict accurately the result of recent well designed trial of other treatments after myocardial infarction. ${ }^{6}$ Moreover, it is unlikely that the 1994 meta-analysis would have shown any benefit on total mortality had only aspirin studies been considered. Worse still, one of the trials suggesting benefit with aspirin lost a third of its patients to follow up and could be regarded as invalid. ${ }^{7}$

The apparent disparity between ISIS- 2 and the other post-infarction trials suggests that the benefits of aspirin on mortality may be confined to the period immediately after myocardial infarction, a view that is supported by several long-term trials. ${ }^{8-12}$ The later the patients were randomised after infarction the less positive the results of the trials became. It should be stressed that it has not been established whether aspirin needs to be continued long term after myocardial infarction to maintain the initial gain or whether a short course gives rise to lasting benefits.

In five substantial trials ${ }^{10-14}$ aspirin was started $>1$ month after infarction and more 
Table 1 Effects of aspirin on total mortality in late-initiation long term studies after myocardial infarction

\begin{tabular}{llllll}
\hline & $\begin{array}{l}\text { Total } \\
\text { deaths } \\
(\%)\end{array}$ & $\begin{array}{l}\text { Vascular } \\
\text { deaths } \\
(\%)\end{array}$ & $\begin{array}{l}\text { Non- } \\
\text { vascular } \\
\text { deaths } \\
(\%)\end{array}$ & $\begin{array}{l}\text { Non-fatal } \\
\text { myocardial } \\
\text { infarction } \\
(\% \text { studies })\end{array}$ & $\begin{array}{l}\text { Non-fatal } \\
\text { stroke } \\
(\%)\end{array}$ \\
\hline $\begin{array}{l}\text { Control } \\
\quad(\mathrm{n}=5667)\end{array}$ & $494(8 \cdot 72)$ & $434(7.66)$ & $60(1.06)$ & $457(8.06)$ & $109(1.92)$ \\
$\begin{array}{c}\text { Aspirin } \\
\quad(\mathrm{n}=6880)\end{array}$ & $602(8 \cdot 75)$ & $513(7 \cdot 46)$ & $89(1.29)$ & $426(6.19)$ & $82(1.19)$ \\
$\begin{array}{c}\text { Events } \\
\text { prevented per } \\
\quad 1000 \text { treated }\end{array}$ & -0.3 & +2.0 & -2.3 & +18.7 & +7.3 \\
$\begin{array}{c}\text { Events prevented } \\
\text { per year per } \\
1000 \text { treated }\end{array}$ & -0.1 & +0.7 & -0.8 & +6.2 & +2.4 \\
\hline
\end{tabular}

Numbers are taken from the 1988 meta-analysis. ${ }^{4}$ Negative numbers indicate an excess of events in aspirin treated groups. Average duration of trials was about 3 years. Note numbers randomised to aspirin and control were unequal.

than $90 \%$ of patient were followed up. In these trials there was not even a trend for aspirin to reduce overall mortality and even the effect on vascular deaths was small (table 1 ), compared for instance with the effect of ACE inhibitors or $\beta$ blockers after infarction. ${ }^{1516}$ Aspirin seemed to reduce non-fatal stroke and non-fatal myocardial infarction. The effect of aspirin on morbidity alone might support its long-term use but, again, the effect on non-fatal events was not large.

Several of the long-term post-infarction trials indicate a trend to an increase in sudden death with aspirin. About $25 \%$ of all myocardial infarctions are not associated with symptoms that are recognised as such. ${ }^{17}$ Aspirin is an analgesic and raises pain threshold even when given in modest doses. ${ }^{18}$ Aspirin may reduce the recognition of myocardial infarction. This might reduce the number of symptomatic, documented acute recurrent infarctions but increase the risk of sudden death owing to failure to deliver adequate treatment, while leaving overall mortality unaffected. Thus the reduction in myocardial infarction by aspirin in long-term studies could be artefactual.

The AMIS and PARIS-II trials both reported the influence of baseline characteristics on outcome (table 2). ${ }^{112}$ The AMIS trial, the largest aspirin study ever conducted in terms of patient years exposure, showed a trend to increased mortality with aspirin in most subgroups studied. Differences in baseline characteristics might have biased the AMIS study against aspirin, but the failure of

Table 2 Effects of Aspirin on total mortality in patients with and without evience of heart failure after myocardial infarction

\begin{tabular}{|c|c|c|c|c|}
\hline & \multicolumn{2}{|l|}{ PARIS II } & \multicolumn{2}{|l|}{$A M I S$} \\
\hline & Placebo & Aspirin & Placebo & Aspirin \\
\hline Total mortality & $114 / 1565(7 \cdot 3)$ & $111 / 1565(7 \cdot 1)$ & $219 / 2267(9 \cdot 7)$ & $246 / 2267(10.9)$ \\
\hline HF Absent & NA & NA & 6.9 & $8 \cdot 3$ \\
\hline HF Present & NA & NA & $21 \cdot 2$ & $23 \cdot 7$ \\
\hline NYHA I & 5.8 & 4.9 & $7 \cdot 3$ & $8 \cdot 6$ \\
\hline NYHA II & 8.9 & $9 \cdot 4$ & $14 \cdot 3$ & $14 \cdot 3$ \\
\hline First infarct & $6 \cdot 2$ & 5.9 & $8 \cdot 1$ & $9 \cdot 2$ \\
\hline$>1$ infarct & $13 \cdot 5$ & $13 \cdot 5$ & $19 \cdot \overline{6}$ & $19 \cdot 2$ \\
\hline \multicolumn{5}{|l|}{ Digoxin: } \\
\hline No & $6 \cdot 3$ & $5 \cdot 5$ & $7 \cdot 4$ & $9 \cdot 3$ \\
\hline Yes & $13 \cdot 7$ & $15 \cdot 6$ & $21 \cdot 0$ & $20 \cdot 8$ \\
\hline
\end{tabular}

aspirin to show significant benefit even among groups stratified for risk does not support this conjecture. ${ }^{12}$ The PARIS-II trial showed an overall trend towards benefit with aspirin but the trend was in the opposite direction among patients with heart failure or major ventricular dysfunction. The evidence supporting the long-term use of aspirin in patients with coronary disease and well preserved ventricular function was supported by data from the Swedish SAPAT study. ${ }^{19}$ Overall the data suggest that long-term aspirin may indeed be helpful in patients with well preserved ventricular function but possibly harmful in high risk patients with major ventricular damage.

Most of the long-term studies of aspirin used doses greater than $900 \mathrm{mg} /$ day; indeed all six of the late initiation studies did. ${ }^{4}$ The high doses of aspirin used in the older trials could have caused harm and the lower doses in current use may be much safer. However, the lowest dose of aspirin used in any longterm post-infarction trial was $300 \mathrm{mg} /$ day. These doses may not be relevant to today's practice but because there are no data to show a long-term benefit from aspirin in doses lower than those studied it is possible that long-term aspirin prophylaxis after myocardial infarction is futile with doses currently advocated. Comparative trials in patients at risk of stroke have not shown any major difference in benefit or harm with doses ranging from 75 to $1200 \mathrm{mg} /$ day $^{5}$ but neither do the studies of lower doses of aspirin show a clear reduction in coronary events compared with placebo in this population. ${ }^{20} 21$

Although aspirin seems to be cheap, treating its side effects may not be. Patients taking aspirin are at a fourfold increased risk of gastrointestinal haemorrhage. ${ }^{22} 23$ Aspirin may account for a third of all major gastrointestinal haemorrhage in subjects over 60 years of age, ${ }^{24}$ those most likely to have heart failure. Currently for every 1000 patients taking aspirin about two each year will have a major gastrointestinal bleed, leading to death in $10 \%$ of cases. ${ }^{22}{ }^{23}$ Many more will have aspirin induced dyspepsia. Prophylaxis of and treatment of dyspepsia with $\mathrm{H} 2$ antagonists or omeprazole and hospital management of haemorrhage is expensive.

Several of the long-term aspirin trials also noted that patients taking high dose aspirin had a higher serum urea and uric acid. ${ }^{11} 12$ Because renal function is often precarious in patients with heart failure this is of some concern. The effect of lower doses of aspirin on renal function in large long-term trials is unknown.

\section{Evidence from large heart failure trials}

There is no evidence of an effect of aspirin on mortality in heart failure, because the issue has not been addressed. The V-HeFT studies suggested that aspirin reduced thromboembolic events, not including myocardial infarction, but this was not a randomised 
comparison. ${ }^{25}$ Myocardial infarction and unstable angina were no less common among those taking aspirin in the SOLVD study placebo group ${ }^{1}$ although little significance can be attached to this finding because patients at higher risk of infarction may have been more likely to receive aspirin.

The clinical trials suggest that stroke is not a very common event in patients with heart failure, at least among the age groups incorporated into the landmark studies reported to date. ${ }^{25-27}$ Interestingly, several studies of patients with heart failure suggest that thromboembolic events are no more common in patients with atrial fibrillation, ${ }^{25} 28$ although studies of atrial fibrillation suggest the contrary..$^{29}$ Greater weight should be put on the latter trials as these were prospective studies.

\section{Is there an interaction between aspirin and ACE inhibitors?}

All the long-term studies on the effects of aspirin on mortality after infarction were conducted before treatment with ACE inhibitors was commonplace. The debate on a potentially harmful interaction between ACE inhibitors and aspirin was initiated when the SOLVD study findings showed that enalapril had no beneficial effect on mortality among those taking aspirin. ${ }^{2}$ No other large mortality trial of heart failure has reported on the effects of aspirin on the improvement in mortality associated with ACE inhibitors. All the post-infarction trials that have reported it show a tendency to less benefit from ACE inhibition among those taking aspirin, ${ }^{15} 30$ with the exception of the SAVE trial. ${ }^{31}$ Even the SAVE trial shows a trend to less benefit on a combined morbidity and mortality outcome among those taking captopril and aspirin. ${ }^{31}$ In the SOLVD trial there was no evidence of an adverse interaction between aspirin and enalapril on recurrent coronary events.

\section{Theoretical basis for the interaction between aspirin and ace inhibitors}

Aspirin inhibits the production of prostaglandins. The prostaglandins are a diverse group of compounds: some are vasodilator and antithrombotic (for example, prostacyclin) others are vasoconstrictor and prothrombotic (for example, the thromboxanes).

Production of vasodilator prostaglandins appear to be an important counter-regulatory pathway in patients with heart failure, ${ }^{32}$ reflecting extensive dysfunctional endothelium. Plasma concentrations of vasodilator prostaglandins are increased and this is proportional to the activation of the reninangiotensin system and the serum sodium concentration. ${ }^{32}$ Thus the response of prostaglandin synthetic pathways to inhibitors may be very different in patients with heart failure than in patients with coronary artery disease and good ventricular function. Patients with heart failure have other evidence of endothelial dysfunction including altered responses to endothelium mediated vasodilators $^{33}$ and raised plasma concentrations of von Willebrand factor and other defects in haemostasis. ${ }^{34} 35$

ACE inhibitors may reduce the degradation of bradykinin and, thereby, enhance production of prostaglandins. ${ }^{36}$ Angiotensin II can also stimulate the production of vasodilator prostaglandins, and ACE inhibition, by reducing angiotensin II production, could theoretically reduce renal prostaglandin synthesis. ${ }^{37} 38$ ACE inhibitors may also reduce production of thromboxanes, much the same as aspirin. ${ }^{39}$ Platelet activation generates angiotensin II which may enhance local vasoconstriction; it is not clear if this can be prevented by ACE inhibitors. ${ }^{40}$ Angiotensin II may, in turn, enhance thromboxane-induced arterial contraction. ${ }^{39}$ The overall effect of ACE inhibitors on prostaglandin synthesis and platelet aggregability remain controversial. ${ }^{36-41}$ But aspirin and ACE inhibitors may exert similar effects in several ways.

Administration of indomethacin to patients with heart failure results in vasoconstriction, a fall in cardiac output, renal blood flow, and glomerular filtration rate. ${ }^{3242}$ Effects are more prominent among patients with hyponatraemia. ${ }^{32}$ High doses of aspirin cause urinary sodium retention but it is not known whether low doses exert similar effects on salt and water metabolism in patients with heart failure. ${ }^{43}$ Inhibition of prostaglandin synthesis may cause hyponatraemia, ${ }^{44}$ an ominous prognostic sign in heart failure. ${ }^{45}$

Several studies have addressed the interaction of aspirin and other inhibitors of prostaglandin synthesis on cardiovascular function. Hall et al noted that single doses of $350 \mathrm{mg}$ of aspirin prevented most of the beneficial central haemodynamic effects of enalapril in patients with severe heart failure. ${ }^{46}$ Nishimura et al used plethysmography to study the effects of indomethacin on captopril induced changes in peripheral haemodynamics in patients with heart failure. ${ }^{47}$ Indomethacin attenuated the effects of captopril. In contrast van Wijngaarden et al could discern no such interaction ${ }^{48}$ but suggested that the use of lower doses of aspirin ( $<300 \mathrm{mg} /$ day) might explain the difference from Hall's study. Schwartz et al studied the effects of captopril and aspirin on renal function in 10 elderly patients with heart failure..$^{49}$ Only one patient had a marked fall in creatinine clearance on receiving the combination treatment. Baur et al also found no important interaction between aspirin (300 $\mathrm{mg})$ and enalapril on haemodynamics or renal function in an 8 week open-label study. ${ }^{38}$ Townend showed that single doses of indomethacin attenuated the increase in cardiac output and renal blood flow in response to captopril but not the increase in forearm or calf blood flow. ${ }^{50}$

Baur et al also studied the effects of aspirin and enalapril on urinary excretion of prostaglandin metabolites. ${ }^{38}$ Their data suggest that enalapril and aspirin may have similar effects on thromboxane metabolism. This 
would support the view that the lack of mortality benefit with ACE inhibition in patients taking aspirin may be the result of a common mechanism of effect.

\section{Conclusion}

The data on the interaction of aspirin and ACE inhibitors are inconclusive. What should the clinician do when faced with the decision to use a combination of an ACE inhibitor and aspirin?

In the weeks after myocardial infarction the benefits of both ACE inhibitors ${ }^{15}$ and aspirin ${ }^{16}$ are well established and, although the benefit from the combination may be reduced, the combination will still be greater than either used alone. For patients with large myocardial infarctions or heart failure warfarin may be a better option than aspirin. ${ }^{16}$ The dose of aspirin used should be around $160 \mathrm{mg} /$ day. $^{45}$

Few treatments are suitable for all patients forever. At present the benefits of indiscriminate aspirin used long-term after infarction remain unproved, and may even be harmful in patients with heart failure. In contrast the benefits of ACE inhibitors in patients with heart failure are well established. ${ }^{155152}$ Therefore, if the clinician is concerned about the potential interaction of aspirin and an ACE inhibitor in patients with post-infarction ventricular dysfunction or heart failure, it seems preferable to stop the aspirin rather than the ACE inhibitor. Warfarin could be used as an alternative to aspirin though the benefits of warfarin in heart failure also remain to be established. ${ }^{53}$

The best solution in the absence of adequate clinical data is to carry out a randomised clinical trial. The Warfarin Aspirin Study of Heart failure (WASH) trial has been set up to compare the effects of no antithrombotic treatment, aspirin, and warfarin on mortality in patients with heart failure. The trial will determine whether aspirin causes significant harm or benefit in a population with heart failure caused predominantly by coronary heart disease.

1 Yusuf S, Pepine CJ, Garces C, Pouleur H, Salem D, Kostis J, et al. Effect of enalapril on myocardial infarction and unstable angina in patients with low ejection fractions. Lancet 1992;340:1173-8.

2 Pitt B. Use of converting enzyme inhibitors in patients with asymptomatic left ventricular dysfunction. $\mathcal{F} A m$ Coll Cardiol 1993;22(suppl A): 158A-61A.

3 Garg R, Yusuf S. Epidemiology of congestive heart failure. In: Barnett DB, Pouleur H, Francis GS. Dekker. 1993.

4 Antiplatelet Trialists' Collaboration. Secondary prevention of vascular disease by prolonged antiplatelet treattion of vascular disease by prol

5 Antiplatelet Trialists' Collaboration. Collaborative overview of randomised trials of antiplatelet therapy-I: view of randomised trials of antiplatelet therapy-I:
Prevention of death, myocardial infarction, and stroke Prevention of death, myocardial infarction, and stroke
by prolonged antiplatelet therapy in various categories by prolonged antiplatelet therapy in
of patients. $B M \mp 1994 ; 308: 81-106$.

6 ISIS-4 Collaborative Group. ISIS-4: a randomised factorial trial assessing early oral captopril, oral mononitrate, and intravenous magnesium sulphate in 58,050 patients
and with suspected acute myocardial infarction. Lancet with suspected ac

7 Breddin K, Loew D, Lechner K, Uberla KK, Walter E, on behalf of the German-Austrian myocardial Infarction study Group (GAMIS). The German-Austrian Aspirin
Trial: A comparison of acetylsalicylic acid, placebo and phenprocoumon in secondary prevention of myocardial infarction. Circulation 1980;62 (Suppl V):V63-71.

8 Elwood PC, Sweetnam PM. Aspirin and secondary mortality after myocardial infarction. Lancet 1979;ii: 1313-5.

9 Elwood PC, Cochrane AL, Burr ML, et al. A randomised controlled trial of acetylsalicylic acid in the secondary prevention of mortality from myocardial infarction. BMF 1974;i:436- 40.

10 The Persantine-Aspirin Reinfarction Study (PARIS) Research Group. Persantine and aspirin in coronary heart disease. Circulation 1980;62:449-62.

11 Klimt CR, Knatterud GL, Stamler J, Meier P. PersantineAspirin Reinfarction Study. Part II. Secondary coronary prevention with persantine and aspirin. $\mathcal{f} \mathrm{Am}$ Coll prevention with persan
Cardiol 1986;7:251-69.

12 Aspirin Myocardial Infarction Study Research Group. A randomized, controlled trial of aspirin in persons recovered from myocardial infarction. $¥ A M A$ 1980;243: 661-8.

13 The Coronary Drug Project Research Group. Aspirin in coronary heart disease. Circulation 1980;62(suppl V): V59-62.

14 Vogel G, Fischer C, Huyke R. Prevention of reinfarction with acetylsalicylic acid. In: Nreddin $K$, Loew $D$, Ueberla K, Dorndorf W, Marx R, eds. Prophylaxis of venous, peripheral, cardiac and cerebral vascular diseases with acetylsalicylic acid. Stuttgart: Schattauer Verlag 1981:123-8.

15 Cleland JGF. ACE inhibitors for myocardial infarction: how should they be used? Eur Heart $f$ 1995;16:153-9.

16 Cleland JGF, McMurray J, Ray S. Overview of postinfarction trials. In: Cleland JGF, ed. Prevention strategies after myocardial infarction. Science Press, London gies after myoca
1994:37-73.

17 Kannel WB, Abbott RD. Incidence and prognosis of unrecognised myocardial infarction: An update on the Framingham Study. $N$ Engl F Med 1984;311:1144-7.

18 Forster C, Anton F, Reeh PW, Weber E, Handwerker HO. Measurement of the analgesic effects of aspirin with a new experimental algesimetric procedure. PAIN 1988;32:215-22.

19 Jull-Moller S, Edvardsson N, Jahnmatz B, Rosen A, Sorensen S, Omblus R. Double-blind trial of aspirin in primary prevention of myocardial infarction in patients with stable chronic angina pectoris. Lancet 1992;340: 1421-5.

20 Boysen G, Soelberg-Sorensen P, Juhler M, Andersen AR, Boss J, Olsen JS et al. Danish very-low dose aspirin after Boss J, Olsen JS et al. Danish very-low dose aspirin after

21 SALT collaborative group. Swedish aspirin low-dose trial (SALT) of $75 \mathrm{mg}$ aspirin as secondary prophylaxis after

22 Sze PC, Reitman D, Pincus MM, Sacks HS, Chalmers TC. Antiplatelet agents in the secondary prevention of stroke: Meta-analysis of the randomized control trials. Stroke 1988;19:436-2.

23 Weil J, Colin-Jones D, Langman M, Lawson D, Logan R Murphy $M$, et al. Prophylactic use of aspirin and risk of peptic ulcer bleeding. BMF 1995;310:827-30.

24 Faulkner G, Prichard P, Somerville K, Langman-MIS Aspirin and bleeding peptic ulcers in the elderly. $B M \mathcal{F}$ 1988;297:1311-3.

25 Dunkman WB, Johnson GR, Carson PE, Bhat G, Farrell $\mathrm{L}$, Cohn JN. Incidence of thromboembolic events in L, Cohn JN. Incidence of thromboembolic events in
vongestive heart failure. Circulation 1993;87(suppl
VI :94-101.

26 Cohn JN, Benedict CR, LeJemtel TH, Grover J, Shindler DM, Shelton B. Risk of thromboembolism in left ventricular dysfunction: SOLVD [abstr] Circulation 1992;86 (suppl I):I-252.

27 Katz SD, Marantz PR, Biasucci L, Jondeau G, Lee K, Brennan C, LeJemtel TH. Low incidence of stroke in ambulatory patients with heart failure: A prospective study. Am Heart f 1993;126:141-6.

28 Middlekauff HR, Stevenson WG, Stevenson LW Prognostic significance of atrial fibrillation in advanced heart failure-a study of 390 patients. Circulation 1991; 84:40-8.

29 Laupacis A, Boysen G, Connolly S, Ezekowitz M, Hart R, James K. Risk factors for stroke and efficacy of antithrombotic therapy in atrial fibrillation: Analysis of pooled data from five randomized controlled trials. Arch Intern Med 1994;154:1449-57.

30 Nguyen KN. Aursnes I, Snappin S, Kjekshus J. Antagonism between enalapril and aspirin: subgroup analysis of the Cooperative New Scandinavian Enalapril Survival Study II (CONSENSUS II). JACC 1995 (supplement A); 25:23A.

31 Pfeffer MA, Braunwald E, Moye LA, Basta L, Brown EJ, Cuddy TE, et al. Effect of captopril on mortality and morbidity in patients with left ventricular dysfunction after myocardial infarction. $N$ Engl f Med 1992; 327:669-77.

32 Dzau VJ, Packer M, Lilly LS, Swartz SL, Hollenberg NK, Williams GH. Prostaglandins in severe congestive heart failure. Relation to activation of the renin-angiotensin system and hyponatremia. $N$ Engl $f$ Med 1984;310:

33 Habib F, Dutka D, Crossman D, Oakley CM, Cleland JGF. Enhanced basal nitric oxide production in heart failure: Another failed counter-regulatory vasodilator mechanism? Lancet 1994;344:371-3. 
34 Sbarouni E, Bradshaw A, Andreotti F, Tuddenham E, Oakley CM, Cleland JGF. Relationship between hemostatic abnormalities and neuroendocrine activity in heart failure. Am Heart $\mathcal{F}$ 1994;127:607-12.

35 Jafri SM, Ozawa T, Mammen E, Levine TB, Johnson C, Goldstein S. Platelet function, thrombin and fibrinolytic activity in patients with heart failure. Eur Heart $\mathcal{f}$ 1993;14:205-12.

36 Zusman RM. Effects of converting-enzyme inhibitors on the renin-angiotensin-aldosterone, bradykinin, and arachidonic acid-prostaglandin systems: correlation of chemical structure and biological activity. Am $\mathcal{J}$ Kidney Dis 1987;10:13-23.

37 Shebuski RJ, Aitken JW. Angiotensin II stimulation of renal prostaglandin synthesis elevates circulating prostacyclin in the dog. $f$ Cardiovasc Pharmacol 1980;2: $667-72$

37 Baur LHB, Schipperheyn J, van der Laarse A, Souverijn JHM, Fröhlich M, de Groot A, et al. Combining salicylate and enalapril in patients with coronary artery disease and heart failure. Br Heart $\mathcal{F}$ 1995;73:227-36.

$38 \mathrm{Lin} \mathrm{L,} \mathrm{Nasjletti} \mathrm{A.} \mathrm{Role} \mathrm{of} \mathrm{endothelium-derived}$ prostanoid in angiotensin-induced vasoconstriction. Hypertension 1991;18:158-64.

39 Ferri C, De Angelis C, Del Porto MA, Luparini RL, Giarizzo C, Santucci A, et al. Blood platelets and angiotensin II: angiotensin II release after platelet aggregation. $\mathcal{F}$ Hypertens 1988;6(suppl):S69-71.

40 Birkebaek NH, Vejby-Christensen H, Jakobsen $P$, Winther $\mathrm{K}$. The effect of nifedipine and captopril on platelet activation and prostanoid production in essenplatelet activation and prostanoid production in essen-

42 Gottlieb SS, Robinson S, Krichten CM, Fisher MI Renal response to indomethacin in congestive heart failure secondary to ischemic or idiopathic dilated cardiomyopathy. Am $f$ Cardiol 1992;70:890-3.

43 Riegger GAJ, Kahles HW, Elsner D, Kromer EP, Kochsiek K. Effects of acetylsalicylic acid on renal func- tion in patients with chronic heart failure. $\mathrm{Am} \mathcal{F} \mathrm{Med}$ 1991;90:571-5.

44 Clive DM, Stoff JS. Renal syndromes associated with non-steroidal anti-inflammatory drugs. $N$ Engl $f \mathrm{Med}$ 1984;310:563-71.

45 Cleland JGF, Dargie HJ, Ford I. Mortality in heart failure: Clinical variables of prognostic value. $\mathrm{Br}$ Heart $\mathrm{f}$ 1987;58:572-82.

46 Hall D, Zeitler H, Rudolph W. Counteraction of the vasodilator effects of enalapril by aspirin in severe heart failure. $¥ \mathrm{Am}$ Coll Cardiol 1992;20:1549-55.

47 Nishimura H, Kubo S, Ueyama M, Kubota J, Kawamura $\mathrm{K}$. Peripheral hemodynamic effects of captopril in patients with congestive heart failure. Am Heart $\mathcal{F} 1989$; patients with

48 van Wijngaarden J, Smit AJ, de Graeff PA, Gilst WH, van der Broek SAJ, van Veldhuisen DJ, et al. Effects of acetylsalicylic acid on peripheral haemodynamics in patients with chronic heart failure treated with ACE inhibitors. F Cardiovasc Pharmacol 1994;23:240-5.

49 Schwartz D, Kornowski R, Lehrman H, Averbuch M, Pines A, Greenland M, et al. Combined effect of captopril and aspirin in renal hemodynamics in elderly patients with congestive heart failure. Cardiology 1992; 81:334-9.

50 Townend JN, Doran J, Lote CJ, Davies MK. Peripheral heamodynamic effects of inhibition of prostaglandin synthesis in congestive heart failure and interactions with captopril. Br Heart $\mathcal{f}$ 1995; 73:434-41.

51 Cleland JGF, Poole-Wilson PA. ACE inhibitors for heart failure: a question of dose. Br Heart $\mathcal{F}$ 1994;72 (suppl Sept):S106-45.

52 Cleland JGF. The clinical course of heart failure and its modification by ACE inhibitors: Insights from recent clinical trials. Eur Heart f 1994;15:125-30.

53 Baker DW, Wright RF. Management of Heart Failure. IV. Anticoagulation for patients with heart failure due to left ventricular systolic dysfunction. $\mathcal{F A M A}$ 1994;272:1614-8. 